\title{
Biosynthesis of Ubiquinone in the Rat
}

\author{
By D. E. M. LAWSON, D. R. THRELFALL, J. GLOVER AND R. A. MORTON \\ Biochemistry Department, University of Liverpool
}

(Received 16 November 1960)

Rüegg et al. (1959) and Linn et al. (1959) have reported that rat liver contains two ubiquinones with $C_{45}$ and $C_{50}$ side chains (coenzymes $Q_{8}$ and $Q_{10}$ respectively), the former predominating. Experiments in this Laboratory confirmed the presence of both these ubiquinones in our stock-colony rats and also showed the presence of traces of ubiquinones with side chains containing 40 and 35 carbon atoms (Lawson, Mercer, Glover \& Morton, 1960). Similar observations have also been made independently by others (Diplock, Edwin, Green, Bunyan \& Marcinkiewicz, 1960).

The occurrence of at least four ubiquinones in the rat raises the question of their origin. One or more may come from the diet, some components of which are known to contain ubiquinone (Page, Gale, Koniuszy \& Folkers, 1959) and others may be formed by intestinal micro-organisms. The similarity between the ubiquinones and vitamins $K_{2}$ suggests that the rat possibly makes use of a preformed substituted benzoquinone moiety, to which it may attach one of a series of polyisoprenoid units in a manner similar to that claimed by Martius \& Esser (1958) for the utilization of 2methyl-1:4-naphthoquinone in the synthesis of vitamin $\mathbf{K}_{\mathbf{2}}$ (with a polyisoprenoid side chain). It has already been shown that $[2-14 \mathrm{C}]$ mevalonate (Gloor \& Wiss, $1959 a$ ) and $\left[1-{ }^{14} \mathrm{C}\right]$ acetate (Dialameh \& Olson, 1959) can be incorporated in vivo into ubiquinone by the rat. The radioactivity was only in the side chain (Wiss, 1959; Gloor, Schindler $\& W$ iss, 1960) so the aromatic nucleus is presumably independently available.

The origin of this substituted quinone portion of the molecule in the animal body is still unknown, although in micro-organisms similar quinones such as aurantiogliocladin (Birch, Fryer \& Smith, 1958) and fumigatin (D. E. M. Lawson, N. M. Packter and J. Glover, unpublished observations) have been shown to be derived from $\left[{ }^{14} \mathrm{C}\right]$ acetate. A number of aromatic compounds have been tested for precursor function. Gloor \& Wiss (1959a) showed that $\left[{ }^{3} \mathrm{H}\right]$ methylfumigatin (3:4-dimethoxy2:5-toluquinone) was not incorporated into ubiquinone in the rat. Again, the nucleus of vitamin E apparently cannot be utilized (Gloor \& Wiss, $1959 a$; Alaupovic \& Johnson, 1959). Further, vitamin $\mathbf{E}$ deficiency does not appear to affect the concentration of ubiquinone in rat tissues
(Morton \& Phillips, 1959), although more recently results have been obtained which are at variance with this and suggest that ubiquinone levels are lowered (Green, Edwin, Diplock \& Bunyan, 1960).

The aim of the study was to determine the portions of the ubiquinone molecule which can be synthesized by the various tissues of the rat. Secondly, it would be useful to know if a particular quinone administered orally can be stored unchanged and utilized in the animal or converted into the other homologues. In the present work, $\left[2-{ }^{14} \mathrm{C}\right]$ acetate was administered intraperitoneally or orally to rats and the specific activities of ubiquinone from intestine, skin and liver were determined. Several experiments have been carried out to measure the incorporation of $\left[2-{ }^{14} \mathrm{C}\right]$ mevalonate into ubiquinone formed in vitro during incubation for 3-9 hr. of everted intestinal sacs (Wilson \& Wiseman, 1954) of the rat. The ebsorption of ubiquinone-45 administered orally in single doses has been studied in the rat and the effect on endogenous ubiquinone-45 levels of adding ubiquinone-50 to the diet has been explored for rat liver and intestine.

\section{EXPERIMENTAL}

Animals. Hooded rats (average weight 160 g.) from the stock colony were used in all experiments. Females were used in Expts. I, II, III, VIII and IX, and males were used in the remainder. The females normally contain a slightly higher level of ubiquinone in the liver than the males (Hemming, 1958; Green et al. 1960). The animals were maintained on food cubes (No. 4 diet, British Extracting Co., Port Sunlight). Special diets, as free as possible from fat-soluble pigments, were, however, substituted when test substances were being administered. This ensured that the spectroscopic examination of intestinal lipids was not made unnecessarily difficult.

Diet no. 1 contained (\%): sucrose, 65; casein, 18; Yestamin, 8 (English Grains Co. Ltd., Burton-on-Trent); arachis oil, 5; salt mixture 4 (Osborne \& Mendel, 1913); choline chloride, $\mathbf{0} \cdot \mathbf{1}$.

Diet no. 2 contrined (\%): sucrose, 70; casein, 20; arachis oil, 5.4; salt mixture 4.3; synthetic vitamin B mixture, $0 \cdot 3$ (Horner, 1958). Vitamin A was given in the form of a premix, each rat receiving 80 i.u. per week. This diet was low in ubiquinone-45 and was used for feeding experiments with ubiquinone-50. Ubiquinone could not be detected in the arachis oil, $20 \mathrm{~g}$. of which were saponified and the unsaponified part was chromatographed on alumina as described below. 
Dosing. In Expt. I, three doses of [2-14C]acetate $(10.4 \mu \mathrm{o}$ in $0.5 \mathrm{ml}$. of $0.9 \% \mathrm{NaCl})$ were injected intraperitoneally on successive days to each of three rats from the stock colony. In Expt. II, two doses of $\left[2{ }^{14} \mathrm{C}\right]$ acetate (16.4 $\mu$ o each) dissolved in water, were taken up on a little dry cellulose powder and admixed with about $3 \mathrm{~g}$. of diet no. 1. The mixture was then formed into small pellets which the starving animals ate readily without loss.

The remainder of the daily supply of diet (about $10 \mathrm{~g}$.) was then given to the animals. In Expt. VIII, the absorption and storage of single doses of ubiquinone were examined with nine female rats from the same litter. Each of four in the test group were given $4.7 \mathrm{mg}$. of ubiquinone45 dissolved in a little arachis oil. After $24 \mathrm{hr}$. the test and five control animals were killed, and their tissues examined for ubiquinone.

During this work the stock diet contained mainly ubiquinone-45, which could have affected the concentration of this homologue in the rat tissues. Therefore, the effect of administering a diet containing predominantly ubiquinone50 on the concentrations of these two homologues in the rat was examined. The relative amounts of each homologue present in the intestines and liver were estimated after chromatographic separation on paper as described below.

The animals were killed by a sharp blow on the back of the head and neck $24 \mathrm{hr}$. after the last dose of ubiquinone or food, and the various tissues excised immediately. Those tissues not analysed right away were stored at $-22^{\circ}$ until they could be extracted.

Preparation of intestinal sacs and incubation procedure. The animals used for the preparation of intestinal sacs were starved for a few hours before killing. The intestines were excised and washed out with $0.9 \% \mathrm{NaCl}$ and everted by the procedure of Wilson \& Wiseman (1954). The lumen was then filled with bicarbonate buffer (Krebs \& Henseleit, 1932) and tied off in appropriate lengths to form sacs for insertion into $150 \mathrm{ml}$. conical flasks. The sacs were just covered with buffer. The labelled substrate was added directly to the buffer medium as required.

In Expts. III, V and VI some carrier ubiquinone was added to the buffer in the form of an aqueous dispersion with crystalline bovine albumin (5 mg./ml.). This enables the ubiquinone to be adsorbed into the mucosal cells. The flasks were fitted with bungs carrying inlet and outlet tubes and connected to an $\mathrm{O}_{2}+\mathrm{CO}_{2}(95: 5)$ gas supply. The outlet from the final flask in the gas train was connected to a vessel containing $10 \% \mathrm{KOH}$ solution to trap any ${ }^{14} \mathrm{CO}_{2}$ or ${ }^{14} \mathrm{C}$-labelled volatile acids evolved. The flasks were then incubated at $37^{\circ}$ in a water bath for the appropriate time with constant shaking at 120 excursions/min. At the end of the incubation the sacs were lifted out and carefully rinsed internally and externally. The suspension medium and washings were then centrifuged at $20000 \mathrm{~g}$ for $20 \mathrm{~min}$. to harvest any loose mucosal cells, which were added to the unbroken intestinal tissue for extraction.

Extraction of ubiquinone from tissues. The respective tissues from each set of animals were then saponified in the presence of pyrogallol as described by Mervyn \& Morton (1959). The unsaponifiable matter (with carrier ubiquinone in certain experiments) was chromatographed on partially deactivated acid-washed alumina (Brockmann grade 3 prepared from grade O, Peter Spence and Co. Ltd., Widnes, Lancs.). The ubiquinone is eluted with $4-6 \%$ of ether in light petroleum (b.p. 40-60\%). Occasionally a second chromatography was carried out on a $10 \mathrm{~g}$. column of Celitesilicic acid $(1: 2, w / w)$ to purify the ubiquinone further. The eluting solvent in this case was $40-60 \%$ benzene in light petroleum. It was then possible to crystallize the ubiquinone from the minimum quantity of ethanol at $0^{\circ}$ and then to recrystallize at room temperature.

In Expt. VIII it was more important from the analytical point of view to have all the ubiquinone from a tissue in

\section{Table 1. Recovery of ubiquinones after paper chromatography}

Preparations were placed as a 4 in. band at the starting line on Whatman no. 3 MM paper coated with petroleum jelly. Developing solvent was $N N$-dimethylformamide containing $2 \%$ of water. Ubiquinone zones were eluted with spectroscopically pure ethanol, and the eluate was made up to known volume. Uq, Ubiquinone.

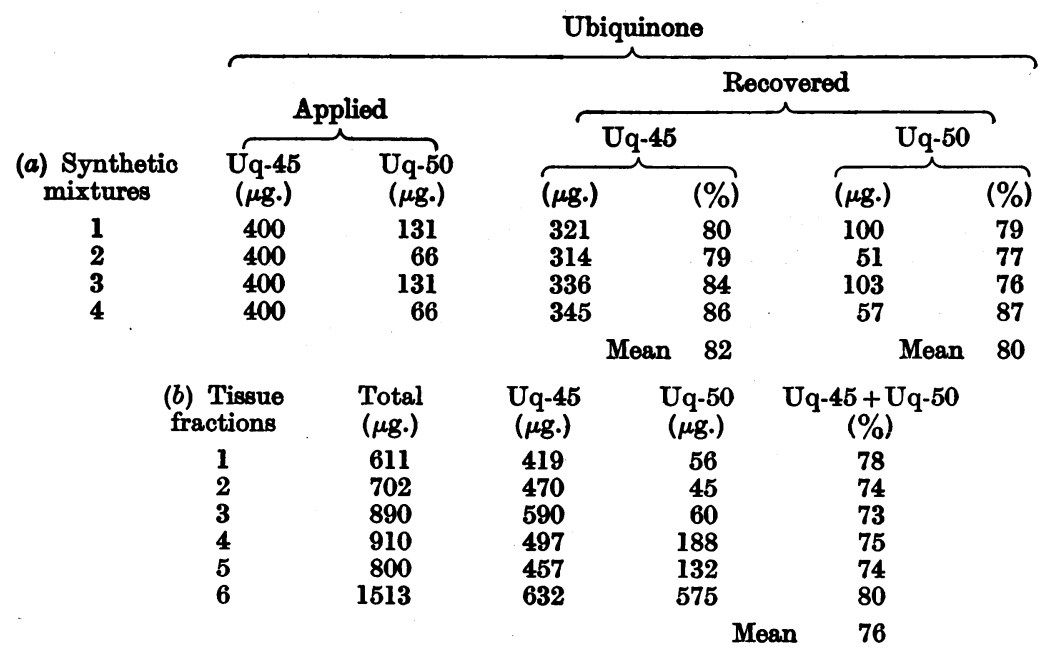


one fraction rather than have a smaller amount of purer material. In this case the ubiquinone was eluted from the alumina column in one fraction with $5 \%$ of ether in light petroleum.

Paper chromatography. The ascending reversed-phase system of Linn et al. (1959) was followed. Whatman paper no. 1 was used for the qualitative analysis and no. 3MM for the quantitative analysis. The paper fibres are coated with petroleum jelly as the stationary phase by dipping the rolled sheet in a $5 \%$ solution in light petroleum and allowing it to drain and dry uniformly. For the quantitative work the petroleum jelly is previously purified by passing a solution in light petroleum through a large column of alumina grade 0 (100 g.). This removed an impurity which absorbs very strongly in the $260 \mathrm{~m} \mu$ region and would interfere with the spectrophotometric assay of the separated ubiquinones when eluted from the paper. A tiny drop of the ubiquinone solution is applied to the paper at the starting point for the qualitative work, but in the quantitative experiments the solution is applied as a narrow band about 4 in. long at the starting line by using a micropipette. The mobile phase is $N N$-dimethylformamide containing $2 \%$ of water. The spots or zones can be located by ultraviolet light and cut out. The ubiquinones are then eluted with spectroscopically pure ethanol into tubes kept in a closed box. The eluate, usually less than $5 \mathrm{ml}$., can be made up to a suitable volume for examination in the spectrophotometer.

The results of analyses of (a) synthetic mixtures and (b) fractions of liver unsaponifiable matter by this procedure are given in Table 1. They show that the recovery is only about $80 \%$. The apparently slightly lower figures for liver fractions are due to the fact that these extracts also contain some ubiquinone-40 and ubiquinone-35 which are not included. The percentage recovery is much the same for both ubiquinone-45 and -50 .

Estimation of ubiquinone. The amounts of ubiquinone in the chromatographic fractions were determined spectrophotometrically after correction for irrelevant absorption by the Morton \& Stubbs (1946) procedure which has been found highly reliable for chromatography fractions containing not less than $20 \%$ of ubiquinone. The extinctions $(E)$ of the extracts in cyclohexane were read at the following three wavelengths: $262 \mathrm{~m} \mu,\left(E_{1}\right), 272 \mathrm{~m} \mu\left(E_{2}\right)$ and $282 \mathrm{~m} \mu$ $\left(E_{3}\right)$. The equation obtained was

$$
E_{\text {oorr. }} \text { at } 272 \mathrm{~m} \mu\left(\lambda_{\max .}\right)=2 \cdot 28\left(2 E_{2}-E_{1}-E_{3}\right) \text {. }
$$

The constant 2.28 was derived from the absorption curve of the pure substance determined on the same spectrophotometer as that used in the routine analyses.
Where irrelevant end-absorption was strong but the maximum at $272 \mathrm{~m} \mu$ was still clear-cut, use was made of the procedure described by Pumphrey \& Redfearn (1960). The drop in $E_{275 \mathrm{~m} \mu}$ was measured on the addition of a crystal of the reductant $\mathrm{NaBH}_{4}$ to the ubiquinone solution in ethanol. The $\Delta E_{1}^{1} \%$ value for pure ubiquinone-50 at $275 \mathrm{~m} \mu$ was 142; and for pure ubiquinone-45 $\Delta E$ was 154 , after allowing for the smaller molecular weight.

Radioassay. Suitable samples of all samples were applied to tared flat stainless-steel planchets of 1 in. diam., previously fitted with a disk of lens tissue ( $0.75 \mathrm{in}$. diam., Green's no. 105) and counted in the proportional region in a hemispherical gas-flow counter (Nuclear Measurements Corp., Chicago, U.S.A.) to $<4 \%$ probable error. All determinations were corrected for background and selfabsorption (to zero thickness) in the usual way.

\section{RESULTS}

Biosynthesis. The various specimens of $\left[{ }^{14} \mathrm{C}\right]$. ubiquinone isolated with carrier ubiquinone-50 from the intestines, skin and livers of rats given [2-14C]acetate either intraperitoneally or orally, were radioactive. The radioactivity persisted even after the second recrystallization. The specific activities corrected for dilution with carrier are given in Table 2. These give a general indication of the radioactivity of the synthesized ubiquinone fraction in each tissue, but the values for the individual homologues may be slightly different. The $E_{1 \mathrm{~m}}^{1 \%}$. values at $272 \mathrm{~m} \mu$ for the crystalline preparations isolated were in good agreement with the expected value for the carrier ubiquinone-50 used. It is evident from Table 2 that the [2-14 C]acetate was incorporated into the ubiquinone of each tissue to different extents depending on the method of administration of the substrate. The specific activities of the pure cholesterol obtained from the same tissues (E. I. Mercer \& J. Glover, unpublished work) are also inserted. The specific activity of the ubiquinone from each tissue is in general greater than that of the corresponding sterol, but the metabolic pool of cholesterol is very much greater.

The results also show clearly that oral administration of the radioactive acetate yields the labelled terpenoid compounds with a much higher specific activity in the intestine.

Table 2. Incorporation of $\left[2-{ }^{14} \mathrm{C}\right]$ acetate into ubiquinone by various tissues of the rat in vivo

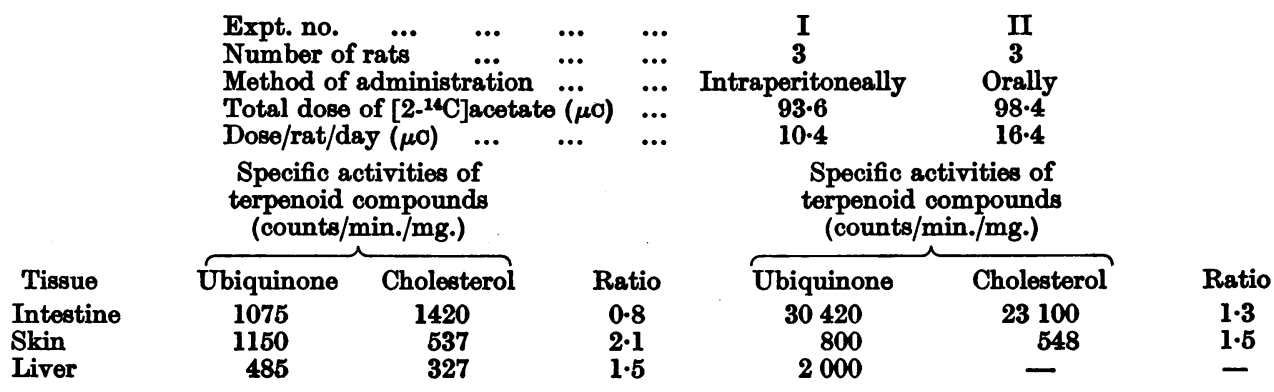


Neither of the above methods of administration completely ruled out the possible participation of intestinal flora in the biosynthesis so a number of experiments were carried out with everted intestinal sacs in vitro. The latter were incubated aerobically with $\left[2-{ }^{14} \mathrm{C}\right]$ mevalonate in KrebsHenseleit buffer for 3-9 hr. in the presence of ubiquinone as trapping agent for $\left[{ }^{14} \mathrm{C}\right]$ ubiquinone. The tissue ubiquinone and carrier were then isolated and purified chromatographically. The ubiquinone fraction was radioactive, so it was crystallized several times to constant specific activity. The Expts. I-III, with ubiquinone-50 as carrier, were done before it was discovered that ubiquinone-45 is the main homologue in the rat. The drop in radioactivity between the second and third crystallizations was attributed to loss of ubiquinone-45 from the crystallization of the ubiquinone-50 carrier. The later experiments were done with ubiquinone-45 as carrier and no such loss of radioactivity occurred after three crystallizations. The results are given in Table 3.

In two experiments, however, where ubiquinone carrier was not added at the outset, the reisolated ubiquinone was unlabelled, which agrees with the findings of Wiss \& Gloor (1960) and Phillips (1960) with rat-liver homogenates. The effect of adding the ubiquinone carrier at the outset of the experiment appears to be significant, although the activity trapped (200 counts/min./mg. or a total of $2 \times 10^{-3} \mu \mathrm{C}$ ) is extremely small in comparison with the amount of $\left[2 .{ }^{14} \mathrm{C}\right]$ mevalonate $(10 \mu \mathrm{C})$ used. It represents an incorporation of $0.02 \%$.

Thus it appears that isolated intestinal tissue can synthesize not only the side chain from small intermediary metabolites such as acetate and mevalonate but can also couple it to the nucleus, the source of which is still unknown.

Location of radioactivity in $\left[{ }^{14} \mathrm{C}\right]$ ubiquinone. In the course of these experiments and parallel work on the absorption of dietary ubiquinone, it was discovered that normal rat liver and intestine con- tained traces of ubiquinone-40 and -35 respectively in addition to the -45 and -50 homologues previously reported (Rüegg et al. 1959; Linn et al. 1959). A mixed $\left[{ }^{14} \mathrm{C}\right]$ ubiquinone specimen diluted with ubiquinone-50 was acetylated and degraded by ozonolysis as described by Morton et al. (1958), and the products were oxidized further to form laevulinic acid and the ring acid which contains the first two carbon atoms of the side chain.

The laevulinic acid was resolved from the ring acid and isolated as the crystalline 2:4-dinitrophenylhydrazone derivative (Rilling \& Bloch, 1959). An attempt was made to obtain the aromatic nucleus in a pure form as the $S$-benzylisothiouronium salt, but the yield was poor and the substance was not easily crystallized. The laevulinic acid carried the bulk of the activity at 46000 counts $/ \mathrm{min} . / \mathrm{m}$-mole, whereas the ring compound possessed only 650 counts $/ \mathrm{min} . / \mathrm{m}$-mole, confirming that the main incorporation of radiocarbon occurred in the side chain.

Storage. From the relatively uniform values reported in the literature for the concentration of ubiquinone in various animal tissues, it appears that large reserves are not accumulated in the liver, unlike vitamin A. The capacity of rat tissues to retain even a temporary reserve was examined in a preliminary experiment VIII, the scale of which was limited by the amount of crystalline ubiquinone-45 available at the time. The ubiquinone contents of various tissues from the group of four dosed females killed $24 \mathrm{hr}$. after dosing are compared with those of the control group in Table 4. Only the liver and intestine of the dosed group contained amounts of ubiquinone-45 in excess of the normal. This suggested that a small reserve may be held but the values for the heart and kidney were unexpectedly a little lower in the test than in the control group. The variation is perhaps due to losses in purifying such small amounts. Of the $4.7 \mathrm{mg}$. administered to each rat only $0.6 \mathrm{mg}$. or $13 \%$ of the dose was recovered from the tissues

Table 3. Incorporation of $\left[2-{ }^{14} \mathrm{C}\right]$ mevalonate into ubiquinone by everted intestinal sacs of the rat

In some experiments carrier ubiquinone was added at the outset to the incubation medium of Krebs-Henseleit bicarbonate buffer containing $5 \mathrm{mg}$. of crystalline bovine albumin/ml. It was invariably necessary to add additional carrier (about $5 \mathrm{mg}$.) for the final crystallizations. Uq, Ubiquinone.

\begin{tabular}{|c|c|c|c|c|c|}
\hline Expt. no. $\quad$... & III & IV & $\mathbf{V}$ & VI & VII \\
\hline $\begin{array}{l}\text { No. and sex of rats ... } \\
\text { Incubation period ( } . . . \\
{[2.14 \mathrm{C}] \text { Mevalonate added }(\mu \mathrm{c})} \\
\text { Ubiquinone carrier (mg.) }\end{array}$ & $\begin{array}{l}\quad 6 \mathrm{~F} \\
3 \\
\mathbf{9} \\
6 \cdot 7(\mathrm{Uq}-50)\end{array}$ & $\begin{array}{c}3 \mathrm{M} \\
\mathbf{3} \\
\mathbf{1 3 \cdot 6} \\
\mathbf{0}\end{array}$ & $\begin{array}{c}6 \mathrm{M} \\
9 \\
10 \cdot 6 \\
9 \cdot 8(\mathrm{Uq}-45)\end{array}$ & $\begin{array}{c}6 \mathrm{M} \\
9 \\
12 \cdot 5 \\
5 \cdot 8(\mathrm{Uq}-45)\end{array}$ & $\begin{array}{c}6 \mathrm{M} \\
9 \\
12 \cdot 5 \\
0\end{array}$ \\
\hline & \multicolumn{5}{|c|}{ Specific activity of $\left[{ }^{14} \mathrm{C}\right]$ ubiquinone isolated (counts/min./mg.) } \\
\hline $\begin{array}{l}\text { Chromatography fraction } \\
\text { After 2nd crystallization } \\
\text { After 3rd crystallization }\end{array}$ & $\begin{array}{r}2270 \\
573 \\
208\end{array}$ & $\begin{array}{r}2667 \\
0 \\
\end{array}$ & $\frac{3800}{198}$ & 1960 & $\begin{array}{r}1456 \\
0\end{array}$ \\
\hline After 4 th crystallization & 200 & - & $\begin{array}{l}198 \\
214\end{array}$ & $\begin{array}{l}158 \\
172\end{array}$ & - \\
\hline
\end{tabular}


$24 \mathrm{hr}$. later. Thus the degree of absorption is poor or else its rate of metabolism and excretion is high. Koniuszy, Gale, Page \& Folkers (1960), however, have reported that small amounts of ubiquinone are excreted in human urine.

The various ubiquinone fractions from the tissues of the above rats were examined qualitatively by reversed-phase paper chromatography. Ubiquinone-45 and -50 were observed in every tissue, with the former in considerable excess. In addition, small amounts of ubiquinone-40 and -35 were detected in fractions from liver, kidney and intestine, but not in the heart or skeletal-muscle preparations. It is possible, however, that, since only small quantities of the latter extracts were available for analysis, ubiquinone-40 and -35 concentrations were below the limit of detection.

A quantitative analysis was carried out on the liver ubiquinones of a group of three female rats (about 2 months old) maintained on the stock cube diet. Out of $611 \mu \mathrm{g}$. applied to the paper the relative proportions of the three major components estimated, ubiquinone-45, -50 and -40 , were 419 , 56 and $27 \mu \mathrm{g}$./liver (av. wt. 5.7 g.) respectively. Ubiquinone-35 was present at a lower level than ubiquinone-40. The recovery of ubiquinone in this analysis was about average (82\%).

Origin of ubiquinone homologues. In order to check whether the ubiquinone-40 and -35 encountered in rat tissue came from the diet, $10 \mathrm{~g}$. of lipid extract (from approx. $280 \mathrm{~g}$. of powdered food cubes) were saponified for $30 \mathrm{~min}$. in the presence of pyrogallol and in a nitrogen atmosphere. The ubiquinones were isolated from the unsaponifiable matter as described above. The content of total ubiquinones was $0.44 \mathrm{mg} . / 100 \mathrm{~g}$. of diet (uncorrected for slight destruction in the saponification of the lipids). The main component was the -45 homologue with only a little -50 . The others were not detected so that the ubiquinone-40 and -35 were synthesized either by the microflora of the intestine or in the rat tissues.

The effect of changing the diet on the ubiquinone pattern in the tissues was examined next. In
Expt. IX, five groups of animals were examined at weekly intervals after being placed on diet no. 2 enriched with ubiquinone-50. The proportions of ubiquinone-45 to -50 were measured in the livers of each group and compared with the corresponding values for controls. The results are given in Table 5 . It became apparent as the experiment progressed that the administered ubiquinone-50 was not affecting the level of ubiquinone-45 in the tissues appreciably so the final group 5 was given supplements of $0.33 \mathrm{mg}$. of ubiquinone-50/rat/day for 3 days before being killed. It is clear from the results that even this relatively high concentration of ubiquinone-50 did not affect the endogenous ubiquinone-45 which tended to remain constant around $130 \mu \mathrm{g} . / \mathrm{g}$. of tissue. Similarly, in the intestine (where the ubiquinone-45 might have been expected to exchange more easily), the same situation was obtained. The values for total ubiquinones in intestinal tissue are given in Table 6, but the proportion of ubiquinone-45 to -50 was only measured in the last group during the period when ubiquinone-50 intake was optimum. It is quite clear from the absolute values and the ratios found, namely $2 \cdot 2$ (experimental) as against $3 \cdot 1$ (control), that dietary ubiquinone-50 has not affected or replaced the endogenous ubiquinone-45. This does not necessarily mean, however, that a metabolic fragment such as the nucleus of ubiquinone-50 may not be used for the biosynthesis of ubiquinone-45.

\section{DISCUSSION}

Although the total amounts of $\left[{ }^{14} \mathrm{C}\right]$ acetate administered by different routes to the two groups of rats in vivo were approximately the same, the specific activities of the $\left[{ }^{14} \mathrm{C}\right]$ ubiquinone isolated from the corresponding organs of the two groups differed widely. The organ or tissue which first received the labelled precursor in highest concentration produced ubiquinone with the greatest specific activity. The intestine had the ubiquinone with highest specific activity in both experiments, reflecting its high rate of metabolism. It is

Table 4. Absorption of single doses of ubiquinone-45 by the rat

Expt. VIII: nine female rats from the same litter were divided into two groups of five (controls) and four (test). Ubiquinone-45 (4.7 mg.) was administered as a single dose in arachis oil to each rat in the test group, $24 \mathrm{hr}$. before it was killed.

\begin{tabular}{|c|c|c|c|c|c|}
\hline \multirow[b]{2}{*}{ Tissue } & \multicolumn{2}{|c|}{ Ubiquinone in controls } & \multicolumn{2}{|c|}{ Ubiquinone in dosed } & \multirow[b]{2}{*}{$(c-a)$} \\
\hline & $\begin{array}{l}(\mu \mathrm{g} . / \text { organ }) \\
(a)\end{array}$ & $\begin{array}{c}(\mu \mathrm{g} . / \mathrm{g} .) \\
(b)\end{array}$ & $\begin{array}{l}\text { ( } \mu \text { g./organ) } \\
\text { (c) }\end{array}$ & $\underset{(d)}{(\mu \mathrm{g} . / \mathrm{g} \cdot)}$ & \\
\hline Intestine & 103 & 18 & 205 & 39 & +102 \\
\hline Liver & 918 & 133 & 1490 & 225 & +572 \\
\hline Heart & 117 & 189 & 96 & 167 & -21 \\
\hline Kidney & 96 & 79 & 67 & 57 & -29 \\
\hline Lung & 7 & 9 & 5 & 7 & -2 \\
\hline Skeletal muscle & - & 27 & - & 18 & -2 \\
\hline
\end{tabular}


Table 5. Storage of dietary ubiquinone-50 in rat liver without any marked effect on the endogenous ubiquinone-45

Expt. IX: there were three female rats in each group. Uq, Ubiquinone.

Controls: Ubiquinone-deficient diet

Week
no.
1
2
3
4
5

Liver wt.
(g.)
$\mathbf{4} \cdot \mathbf{0}$
$\mathbf{5 \cdot 7}$
$\mathbf{6} \cdot 5$
$\mathbf{5} \cdot \mathbf{2}$
$\mathbf{5 \cdot 3}$

Ubiquinone contents ( $\mu \mathrm{g} \cdot / \mathrm{g}$.)

$\begin{array}{cccc}\begin{array}{c}\text { Total } \\ 127\end{array} & \text { Uq-45* } & \text { Uq-50* } & \text { Ratio } \\ 124 & - & -1 & - \\ 120 & 112 & 11 & 10 \cdot 2 \\ 146 & 109 & 11 & 9 \cdot 9 \\ 172 & 152 & 13 & 10 \cdot 1 \\ \text { alues ( } \pm \text { s.E.M.): } & 127( \pm 20) & 13 & 9 \cdot 6 \\ & 12 & 9 \cdot 9\end{array}$

Experimental: Above diet with ubiquinone-50 added (1 mg./100 g. of diet)

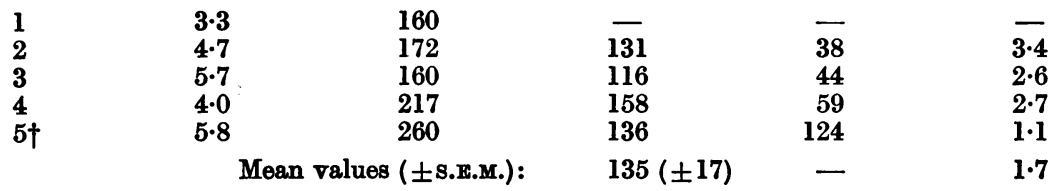

* These values are corrected for the slight loss of material in the chromatographic separation.

† Each rat in group 5 was given a supplement of ubiquinone-50 (1 mg./day) for 3 days before it was killed.

Table 6. Ubiquinone in the intestines of rats on a diet enriched with ubiquinone-50

Expt. X: there were three female rats in each group; the enriched diet contained $1 \mathrm{mg}$. of ubiquinone-50/100 g. of diet. Each rat in the last experimental group was given a supplement of ubiquinone-50 (1 mg./day) for 3 days before examination. Uq, Ubiquinone.

\begin{tabular}{|c|c|c|c|c|}
\hline \multirow[b]{2}{*}{ Week } & \multicolumn{2}{|c|}{ 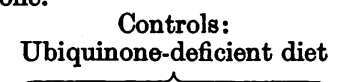 } & \multicolumn{2}{|c|}{$\begin{array}{l}\text { Experimental: } \\
\text { Uq-50-enriched diet }\end{array}$} \\
\hline & $\begin{array}{l}\text { Intestine } \\
\text { wt. } \\
\text { (g.) }\end{array}$ & $\begin{array}{c}\text { Total } \\
\text { ubiquinones } \\
(\mu \mathrm{g} . / \mathrm{g} .)\end{array}$ & $\begin{array}{c}\text { Intestine } \\
\text { wt. } \\
\text { (g.) }\end{array}$ & $\begin{array}{c}\text { Total } \\
\text { ubiquinones } \\
(\mu \mathrm{g} . / \mathrm{g} .)\end{array}$ \\
\hline \multirow[t]{2}{*}{$\begin{array}{l}\text { 1st } \\
\text { 2nd } \\
\text { 3rd } \\
\text { 4th } \\
\text { 5th* }\end{array}$} & $\begin{array}{l}15 \\
14 \\
12 \\
15 \\
14\end{array}$ & $\begin{array}{l}30 \\
31 \\
24 \\
31 \\
40\end{array}$ & $\begin{array}{l}10 \\
14 \\
16 \\
13 \\
17\end{array}$ & $\begin{array}{l}32 \\
37 \\
22 \\
32 \\
40\end{array}$ \\
\hline & Mea & $31 \pm 6$ & Mean & $33 \pm 7$ \\
\hline
\end{tabular}

significant that the values run fairly parallel to those for the pure cholesterol from the same tissue. Together these findings lead to the conclusion that the side chain at least must have been elaborated in each tissue, and not in one organ alone.

Since the metabolic pool of cholesterol is very much larger than that of ubiquinone (about 100 times), the total radioactivity incorporated into the sterols was very much greater, in agreement with the findings of Gloor \& Wiss $(1959 a)$. The turnover rate of the isoprenoid side chain of ubiquinone must therefore be very much slower than that of cholesterol. Presumably it is elaborated in the form of the pyrophosphate in a manner similar to that for farnesyl pyrophosphate and nerolidyl pyrophosphate (Lynen, Eggerer, Henning \& Kessel, 1958; Goodman \& Popják, 1960). If it is formed from mevalonate almost as rapidly as the latter pyrophosphates then the slow turnover rate indicates that the final stages of ubiquinone biosynthesis, such as the coupling of the side chain to the nucleus, are probably rate-limiting. The work of Gloor \& Wiss $(1959 a)$ indicates that the preformed nucleus in the form of 3:4-dimethoxy-2:5toluquinone cannot be used for the biosynthesis so some modified structure must be found.

The incorporation of the small but significant amount of $\left[2-{ }^{14} \mathrm{C}\right]$ mevalonate into intestinal ubiquinone in vitro when carrier material is added whereas none is found in its absence requires comment. The difference between the results can hardly be attributed to microbiological synthesis even though the incubation period was $9 \mathrm{hr}$. in some cases, for bacteria usually elaborate the -30 and -35 homologues. A small amount of the nucleus precursor should be present in the tissue when it is 
excised from the animal so that the newly synthesized ${ }^{14} \mathrm{C}$-labelled side chain may become coupled to it. The carrier ubiquinone added at the outset may merely have a protecting or sparing effect on this new material during the incubation period. Alternatively, it could perhaps on metabolism provide some of the nuclear moiety required for the biosynthesis of new ubiquinone. The turnover of ubiquinone in vivo appears relatively slow from Expts. I and II: therefore one cannot expect rapid incorporation of radioactivity in vitro. The solution of the problem may be obtained by using ubiquinone labelled with ${ }^{14} \mathrm{C}$ in the ring. The experiment conducted by Rudney \& Sugimura (1960) on the administration to rats of $\left[{ }^{14} \mathrm{C}\right] \mathrm{ubi}$ quinone-30 prepared from yeast grown in the presence of sodium [ $\left.{ }^{14} \mathrm{C}\right]$ formate is inconclusive. These authors reported that the nucleus of ubiquinone-30 could not provide the nucleus of ubiquinone-50. This material presumably carries the ${ }^{14} \mathrm{C}$ on the methoxyl group and this may be quite labile as suggested by recent evidence in this Laboratory with $\left[\right.$ methyl- $\left.{ }^{14} \mathrm{C}\right]$ methionine. The methyl group of methionine can provide the methoxyl-methyl of ubiquinone in the rat and may be transferred by an $O$-methyl transferase (Lawson \& Glover, 1961). It would appear that a series of 'activated ' polyisoprenoid unitsarenormally present in rat tissues as intermediates in the biosynthesis of terpenoid compounds such as the sterols, side chains of vitamins $E$ and $K$, ubiquinones and ubichromenol, and dolichol (Pennock, Hemming \& Morton, 1960). The size of side chain coupled to the quinone nucleus is probably controlled by the specificity of the particular enzyme in the organism under study.

The results for the administration of ubiquinone45 and -50 to rats (Tables 4 and 5) indicate that a little storage of ubiquinone takes place in the liver but probably at a site different from that of the endogenous ubiquinone-45, since the concentration of the latter is not appreciably affected by the administration of ubiquinone-50 (see Table 5). Yet during this period of 5 weeks the level of ubiquinone-50 in the liver rose steadily from an average level of $13 \mu \mathrm{g} . / \mathrm{g}$. to $124 \mu \mathrm{g} . / \mathrm{g}$. In the intestine, the ubiquinone-45 level also remains very steady despite the transit of much more ubiquinone-50 across the gut wall. These observations lead to the conclusion that dietary ubiquinone-50 does not easily replace the endogenous material, which is found mainly in the mitochondria (Hemming, Pennock \& Morton 1958) and it may be stored elsewhere in the cell.

The ratio of ubiquinone-45 to -50 in the livers of the control rats on the synthetic diet (low in ubiquinones) was approximately $9 \cdot 9: 1$, which is a little higher than that found by Gloor \& Wiss
$(1959 b, 1960)$ but much higher than the values $5 \cdot 0-5 \cdot 6$ observed by Olson \& Dialameh (1960) and 2.2-3.0 obtained by Wiss \& Gloor (1960) for normal and vitamin A-deficient rats. Our own stockcolony rats on the food cubes known to contain mainly ubiquinone-45 show a ratio in the region of $7 \cdot 5: 1$. These differences should probably be attributed more to dietary effects than to intestinal flora or variations of strain.

In the control groups of rats (see Tables 5 and 6) the ratio for the liver is quite different from the ratio (between 2:1 and 3:1) for the intestine.

Possibly each tissue manufactures its own characteristic proportion as it is known to do with the sterols. Unlike the latter, however, dietary ubiquinone does not appear to affect the synthesis of the endogenous material.

Attention should perhaps be turned to smaller molecules as potential sources of the ring nucleus of ubiquinone. Whereas the ubiquinone molecule appears to be assembled mainly within the tissue cell, the quinone nucleus may be obtained from an outside source.

\section{SUMMARY}

1. The isoprenoid side chain of ubiquinone can be synthesized from acetate by each tissue of the rat in vivo. The rate of incorporation of $\left[2 .{ }^{14} \mathrm{C}\right]$ acetate into ubiquinone, however, is much slower than into cholesterol.

2. Small but significant amounts of $[2-14 \mathrm{C}]$ mevalonate can be incorporated into ubiquinone by the everted intestinal sac in the presence of unlabelled ubiquinone supplements. A small quantity of aromatic nucleus is apparently available in the tissue under these conditions.

3. The tissues of normal stock-colony rats contain mainly ubiquinone-45 with smaller amounts of the $-50,-40$ and -35 homologues in that descending order. The relative proportions in the liver are affected by dietary ubiquinones, which can be stored there temporarily.

4. The administration of ubiquinone-50, however, in amounts from 100 to $450 \mu \mathrm{g}$./rat/day did not affect the concentrations of ubiquinone-45 in liver and intestine, which tend to remain constant at about 130 and $32 \mu \mathrm{g} . / \mathrm{g}$. of tissue respectively. It appears therefore that the exogenous ubiquinone cannot exchange with or flush out the endogenous material which is in the mitochondria. It is presumably localized in another part of the cell and may therefore not be functional in the animal itself.

We wish to thank F. Hoffmann-La Roche and Co. Ltd. for the gift of the [2-14C]mevalonate. One of us (D.E.M.L.) is in receipt of a D.S.I.R. Fellowship. 


\section{REFERENCES}

Alaupovic, P. \& Johnson, B. C. (1959). Arch. Biochem. Biophys. 84, 247.

Birch, A. J., Fryer, R. I. \& Smith, H. (1958). Proc. chem. Soc., Lond., p. 343.

Dialameh, G. H. \& Olson, R. E. (1959). Fed. Proc. 18, 214.

Diplock, A. T., Edwin, E. E., Green, J., Bunyan, J. \& Marcinkiewicz, S. (1960). Nature, Lond., 186, 554.

Gloor, U., Schindler, O. \& Wiss, O. (1960). Helv. chim. acta, 43, 2089.

Gloor, U. \& Wiss, O. (1959a). Arch. Biochem. Biophys. 83, 216.

Gloor, U. \& Wiss, O. (1959b). Biochem. biophys. Res. Commun. 1, 182.

Gloor, U. \& Wiss, O. (1960). Biochem. biophys. Res. Commun. 2, 222.

Goodman, D. S. \& Popják, G. (1960). Biochem. J. 74, 35 P.

Green, J., Edwin, E. E., Diplock, A. T. \& Bunyan, J. (1960). Biochem. biophys. Res. Commun. 2, 388.

Hemming, F. W. (1958). Ph.D. Thesis: University of Liverpool.

Hemming, F. W., Pennock, J. F. \& Morton, R. A. (1958). Biochem. J. 68, 29 P.

Horner, A. A. (1958). Ph.D. Thesis: University of Liverpool.

Koniuszy, F. R., Gale, P.H., Page, A.C., jun. \& Folkers, K. (1960). Arch. Biochem. Biophys. 87, 289.

Krebs, H. A. \& Henseleit, K. (1932). Hoppe-Seyl. Z. 210, 23.

Lawson, D. E. M. \& Glover, J. (1961). Biochem. biophys. Res. Commun. (in the Press).

Lawson, D. E. M., Mercer, E. I., Glover, J. \& Morton, R. A. (1960). Biochem. J. 74, 38P.
Linn, B. O., Page, A. C., jun., Wong, E. L., Gale, P. H., Shunk, C. H. \& Folkers, K. (1959). J. Amer. chem. Soc. 81, 4007.

Lynen, F., Eggerer, H., Henning, W. \& Kessel, I. (1958). Angew. Chem. 70, 739.

Martius, C. \& Esser, H. O. (1958). Biochem. Z. 331, 1.

Mervyn, L. \& Morton, R. A. (1959). Biochem. J. 72, 106.

Morton, R. A., Gloor, U., Schindler, O., Wilson, G. M., Chopard-dit-Jean, L. H., Hemming, F. W., Isler, O., Leat, W. M. G., Pennock, J. F., Rüegg, R., Schwieter, U. \& Wiss, O. (1958). Helv. chim. acta, 41, 2343.

Morton, R. A. \& Phillips, W. E. J. (1959). Biochem. J. 73, 427.

Morton, R. A. \& Stubbs, A. L. (1946). Analyst, 71, 845.

Olson, R. E. \& Dialameh, G. H. (1960). Biochem. biophys. Res. Commun. $2,198$.

Osborne, T. O. \& Mendel, L. B. (1913). J. biol. Chem. 15, 311.

Page, A. C., jun., Gale, P. H., Koniuszy, F. \& Folkers, K. (1959). Arch. Biochem. Biophys. 85, 474.

Pennock, J. F., Hemming, F. W. \& Morton, R. A. (1960). Nature, Lond., 186, 470.

Phillips, W. E. J. (1960). Canad. J. Biochem. Physiol. 38, 1105.

Pumphrey, A. M. \& Redfearn, E. R. (1960). Biochem. J. 76, 61.

Rilling, H. C. \& Bloch, K. (1959). J. biol. Chem. 234, 1424.

Rudney, H. \& Sugimura, T. (1960). Fed. Proc. 19, 220.

Rüegg, R., Gloor, U., Goel, R. N., Ryser, G., Wiss, O. \& Isler, O. (1959). Helv. chim. acta, 42, 2616.

Wilson, T. H. \& Wiseman, G. (1954). J. Physiol. $123,116$.

Wiss, O. (1959). Akzeleration und Ernahrung. Fettlösliche Wirkstoffe, 4. Darmstadt: Steinkopf Verl.

Wiss, O. \& Gloor, U. (1960). Vitam. \& Horm. 19 (in the Press). 